medRxiv preprint doi: https://doi.org/10.1101/2021.08.11.21261692; this version posted August 13, 2021. The copyright holder for this preprint (which was not certified by peer review) is the author/funder, who has granted medRxiv a license to display the preprint in perpetuity.

It is made available under a CC-BY 4.0 International license .

\title{
Estimating the effects of accelerated partner therapy (APT) on reinfection of index cases with chlamydia: a mathematical modelling study
}

Christian L. Althaus, ${ }^{1}$ Claudia S. Estcourt, ${ }^{2}$ Nicola Low ${ }^{1}$

${ }^{1}$ Institute of Social and Preventive Medicine, University of Bern, Bern, Switzerland

${ }^{2}$ School of Health and Life Sciences, Glasgow Caledonian University, Glasgow, UK

Correspondence to: christian.althaus@ispm.unibe.ch

\begin{abstract}
Objectives The expected effects of accelerated partner therapy (APT) on the reinfection of treated index cases by untreated partners with Chlamydia trachomatis (chlamydia) remain unclear. We analyzed data from the LUSTRUM cluster cross-over randomised controlled trial (RCT) using a mathematical model and quantified the effects of offering APT on the probability of successful partner treatment.

Methods We extended a previously developed mathematical model to compute the probability of chlamydia reinfection of index cases by their untreated partners with chlamydia. We fitted the model to data from the RCT and estimated the probability of successful treatment of the partner of index cases using a Bayesian framework.
\end{abstract}

Results We estimated the median probability of reinfection with chlamydia at $16.3 \%(50 \%$ credible interval, Crl: $12.7-20.0 \%$ ) without partner treatment and $2.3 \%$ (50\% Crl: $1.7-3.6 \%)$ when partner treatment is $100 \%$ successful. The observed rates of reinfection in the RCT were $6.7 \%$ (95\% confidence interval, $\mathrm{Cl}$ : 5.6-8.0\%) during the control period (standard partner notification (PN)) and 4.8\% (95\% Cl: 3.7-5.9\%) during the intervention period where APT was offered in addition to standard PN. These rates correspond to a median probability of successful partner treatment of $63 \%$ (50\% Crl: $47-76 \%)$ during the control period and $78 \%$ (50\% Crl: $65-87 \%)$ during the intervention period.

Conclusions Our study suggests that the observed reduction in reinfection with chlamydia when offering APT is consistent with a higher probability of successful partner treatment.

\section{INTRODUCTION}

Reinfection of treated index cases by untreated partners with Chlamydia trachomatis (chlamydia) is common and can lead to further transmission and increases the risk of complications after infection. ${ }^{1}$ Partner notification (PN), the process of identifying, testing and treating sex partners of index cases with a sexually transmitted infection (STI), plays a key role in limiting reinfection in people who have been treated for chlamydia. ${ }^{2}$ Improved PN methods can offer the opportunity to prevent reinfection of index cases more effectively. Expedited partner therapy (EPT) is a method of enhanced patient referral where sexual partners receive medication from the index cases without prior medical evaluation 1 Accelerated parper therapy (APT) is an adaptation of EPT and additionally includes a practice. Accelerated partner therapy (APT) is an adaptation of EPT and additionally includes a 
medRxiv preprint doi: https://doi.org/10.1101/2021.08.11.21261692; this version posted August 13, 2021. The copyright holder for this preprint (which was not certified by peer review) is the author/funder, who has granted medRxiv a license to display the preprint in perpetuity.

It is made available under a CC-BY 4.0 International license .

clinical assessment of sex partners through telephone-led or face-to-face consultation with an appropriately qualified healthcare professional. ${ }^{3}$ Since APT aims to reduce the time to partner treatment and increase the proportion of partners treated, it is important to quantify the potential effects of APT on the reinfection of index cases with chlamydia.

The Limiting Undetected Sexually Transmitted infections to RedUce Morbidity (LUSTRUM) cluster cross-over randomised controlled trial (RCT) in the UK aims to determine the effectiveness of APT among opposite-sex partners with chlamydia. ${ }^{4}$ The primary outcome of the RCT was the proportion of index patients with a positive chlamydia test 12-24 weeks after treatment. ${ }^{5}$ The LUSTRUM RCT is accompanied by a dynamic transmission model of chlamydia to study the potential effects of APT at the population level and a cost-effectiveness analysis of APT compared to standard PN over a period of 5 years. ${ }^{67}$ Mathematical models can also be used to study the effects of different PN strategies on the reinfection of index cases with chlamydia and thus offer a helpful tool to better understand the results from the $\mathrm{RCT}^{2}$

In this study, we analyzed the outcome of the LUSTRUM cluster cross-over randomised controlled trial (RCT) using a mathematical model and quantified the effects of offering APT in addition to standard PN on the probability of successful partner treatment. We estimated the probability of successful treatment of the partner of index cases after the control and intervention period of the RCT.

\section{METHODS}

\section{Mathematical model}

We extended a previously published mathematical model to compute the probability of chlamydia reinfection of index cases by their untreated sexual partners: ${ }^{2}$

$p_{r}=p_{s} \times p_{i} \times\left(\frac{f \times \beta}{f \times \beta+\gamma+\sigma+\delta+\omega}+(1-\epsilon) \times \frac{\delta}{f \times \beta+\gamma+\sigma+\delta+\omega} \times \frac{f \times \beta}{f \times \beta+\gamma+\sigma+\omega}\right)$

where $p_{s}$ is the probability that the index case will have future sex with the partner and $p_{i}$ is the chlamydia-positivity in the infected partner. The first term in the brackets corresponds to the probability that a successfully treated index case is reinfected before the infection in the partner is cleared, the sexual partnership ends, the partner is successfully treated, or the follow-up period ends. $f$ denotes the frequency of sex acts and $\beta$ is the per sex act transmission probability between the index case and partner. $1 / \gamma$ is the average duration of chlamydia infection in the infected partner and $1 / \sigma$ is the average duration of the sexual partnership. $1 / \delta$ is the average time to partner treatment and $1 / \omega$ corresponds to the follow-up period. The second term in the brackets represents the probability of reinfection of index cases when the partner has not been successfully treated. $\varepsilon$ is the probability of successful treatment of the partner of index cases.

\section{Parameters and Bayesian inference}

We first calculated the expected probability of chlamydia reinfection $p_{r}$ as a function of the probability of successful partner treatment. To this end, we sampled $10^{5}$ parameter sets from uniform $(U(a, b)$ from $a$ to $b)$ or binomial $(B(n, p)$ with sample size $n$ and probability $p)$ distributions that were informed by the RCT or literature. $p_{s}$ was drawn from $B(2589,47 \%)$, 
medRxiv preprint doi: https://doi.org/10.1101/2021.08.11.21261692; this version posted August 13, 2021. The copyright holder for this preprint (which was not certified by peer review) is the author/funder, who has granted medRxiv a license to display the preprint in perpetuity.

It is made available under a CC-BY 4.0 International license .

which corresponds to the reported probability that the index case will have future sex with the partner in the control arm of the RCT. ${ }^{5} p_{i}$ was drawn from the overall chlamydia-positivity in partners who returned the STI self-sampling kit in the RCT $(B(120,65 \%)){ }^{5}$ The frequency of sex acts $f$ and the per sex act transmission probability $\beta$ were drawn from $U(1,7)$ per day and $U(6 \%, 16.7 \%)$, respectively. ${ }^{2}$ The average duration of infection $1 / \gamma$ and sexual partnership $1 / \sigma$ were drawn from $U(6,12)$ months and $U(1$ week, 6 months $) .{ }^{2}$ The average time to partner treatment $1 / \delta$ was set to 3.2 days. ${ }^{6}{ }^{8}$ Finally, the follow-up period for the primary outcome of chlamydia-positivity was drawn from $U(12,24)$ weeks. ${ }^{5}$

In a second step, we generated prior distributions of the expected probability of chlamydia reinfection during the control and intervention period of the RCT. We used $p_{s}$ for the control period as described above and drew from $B(2218,52 \%)$ for the intervention period. ${ }^{5}$ Furthermore, we drew the probability of successful treatment of the partner $\varepsilon$ from $U(0,1)$. We then used Approximate Bayesian Computation to generate posterior distributions of $\varepsilon$ for the control and intervention period by rejecting those parameter sets where $p_{r}$ was outside the $95 \%$ confidence interval $(\mathrm{Cl})$ of the chlamydia-positivity in index cases after the control and intervention period, i.e., the primary outcome of the RCT. The reported chlamydia-positivity from the RCT was $6.7 \%(95 \% \mathrm{Cl}: 5.6-8.0 \%)$ after the control period and $4.8 \%$ (95\% Cl: $3.7-5.9 \%)$ after the intervention period where APT was offered in addition to standard PN. ${ }^{5}$

\section{RESULTS}

Increasing the probability of successful partner treatment can substantially reduce the probability of reinfection in the modelled population of the RCT (figure 1). Without partner treatment, the median probability of reinfection with chlamydia would be $16.3 \%(50 \%$ credible interval, $\mathrm{Crl}: 12.7-20.0 \%$ ) after the follow-up period of 12-24 weeks. The British Association for Sexual Health and HIV (BASHH) recommends at least 0.6 contacts per index case for effective PN for chlamydia. ${ }^{9}$ Assuming $60 \%$ successful partner treatment in the modelled RCT, we estimated the probability of reinfection of the index case at $7.9 \%(50 \%$ Crl: $6.1-10.1 \%)$. Finally, the estimated probability of reinfection drops to $2.3 \%(50 \% \mathrm{Crl}$ : $1.7-3.6 \%$ ) for the case when partner treatment is $100 \%$ successful. In general, every $10 \%$ increase in the probability of successful partner treatment results in $1.4 \%(95 \% \mathrm{Crl}$ : $0.4-2.1 \%$ ) absolute reduction in the probability of reinfection.

We estimated the probability of successful treatment of the partner of index cases during the control and intervention period of the RCT. We found that the observed chlamydia-positivity after the control period is consistent with a median probability of successful partner treatment of $63 \%$ (50\% Crl: $47-76 \%$ ). The lower chlamydia-positivity after the intervention period requires a higher probability of successful partner treatment of $78 \%(50 \% \mathrm{Crl}$ : $65-87 \%$ ). Hence, the model suggests that offering APT in addition to standard PN in the intervention period increased the probability of successful partner treatment by $14 \%$ (50\% Crl: $-4-32 \%)$. 


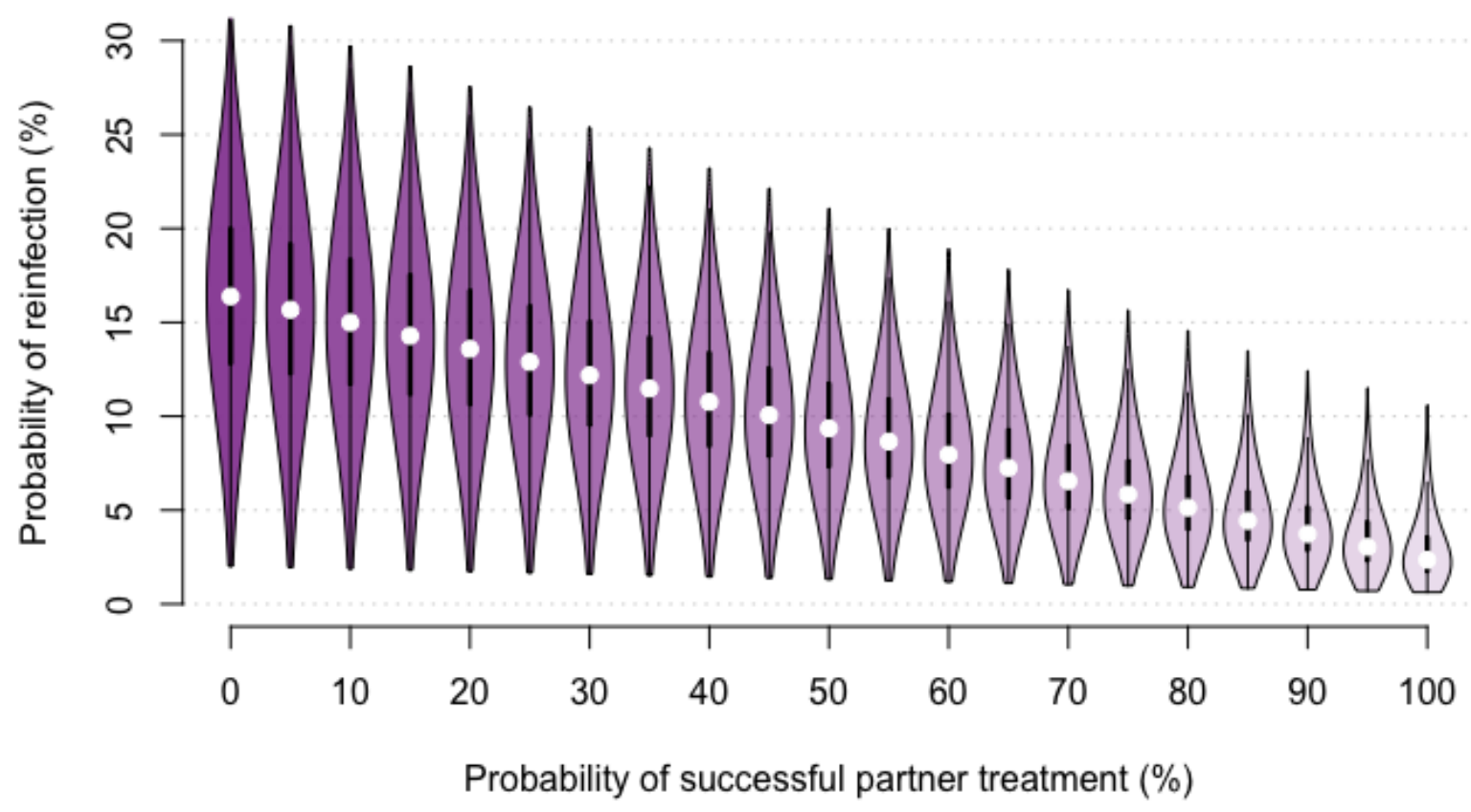

Figure 1 Probability of chlamydia reinfection of index cases by their partners. Posterior distributions of the probability of reinfection are based on $10^{5}$ randomly sampled parameter sets.

\section{DISCUSSION}

We used a mathematical model to study the effects of PN on reinfection of index cases with chlamydia and to analyze the primary outcome of the LUSTRUM cluster cross-over RCT. We showed that the probability of reinfection is expected to decrease linearly with increasing partner treatment. We estimated that offering APT in addition to standard PN in the intervention period of the RCT increased the probability of successful partner treatment from $63 \%(50 \% \mathrm{Crl}: 47-76 \%)$ during the control period to $78 \%(50 \% \mathrm{Crl}: 65-87 \%)$ during the intervention period.

The strength of our study is the application of a mathematical model to study the outcome of an RCT. Using a Bayesian framework allowed us to take into account the considerable uncertainty in critical model parameters, such as the per sex act transmission probabiliy of chlamydia or the average duration of the sexual partnership between the index case and the partner. Furthermore, we were able to include additional data from the RCT in our model, such as the likelihood of future sex with a partner or the chlamydia-positvity in partners who returned the STI self-sampling kit. Nevertheless, there are a number of limitations. First, we did not consider reinfection in women and men separately due to the limited sample size of the RCT. We expect the benefits of offering APT to women and men to be similar, however. Second, the presented mathematical model considers reinfection and treatment from the current partner only. Third, due to the relatively small difference in the primary outcome of the RCT and the use of broad prior parameter distributions, the estimated increase in the 
medRxiv preprint doi: https://doi.org/10.1101/2021.08.11.21261692; this version posted August 13, 2021. The copyright holder for this preprint (which was not certified by peer review) is the author/funder, who has granted medRxiv a license to display the preprint in perpetuity.

It is made available under a CC-BY 4.0 International license.

probability of successful partner treatment during the intervention period comes with uncertainty.

Reinfection of index cases with chlamydia as estimated by the model and observed in the RCT was lower than findings from an earlier RCT on the effects of expedited partner therapy (EPT) that showed persistent or recurrent chlamydia infection in $13 \%$ of participants assigned to standard PN and $10 \%$ assigned to EPT. ${ }^{1}$ The reinfection rates were also considerably lower than the observed $15 \%$ positivity of repeated tests following a positive chlamydia test in an analysis of health insurance claims data. ${ }^{10}$ However, the observed rates of reinfection in the LUSTRUM cluster cross-over RCT are consistent with the modelled estimates and resulted in an estimated probability of successful partner treatment after the control period of $63 \%$. This estimate is consistent with the BASHH recommendation to contact at least 0.6 partners of index cases for effective $\mathrm{PN} .{ }^{9}$ The higher probability of successful partner treatment of $78 \%$ during the intervention period is also consistent with a) the higher proportions of more than one sex partner treated and $b$ ) the higher proportion of treated partners as observed in the RCT. ${ }^{5}$

This study helps to better understand the outcomes of the LUSTRUM cluster cross-over RCT. Our analysis illustrates that the reported chlamydia-positivity in index cases after the intervention period compared to the control period is consistent with a higher probability of successful partner treatment. Hence, our results suggest that offering APT in addition to standard PN increases the probability of successful partner treatment and thereby reduces reinfection of index cases with chlamydia.

\section{Contributors}

All authors conceived and designed the study. CLA developed the mathematical model, conducted the analysis, and wrote the manuscript. All authors contributed to the interpretation of the results, commented on the manuscript, and approved the final version of the manuscript.

\section{Funding}

This study was funded by the National Institute for Health Research (NIHR) Programme Grants for Applied Research (Grant Reference Number RP-PG-0614-20009). The views expressed are those of the authors and not necessarily those of the NIHR or the Department of Health and Social Care.

\section{Competing interests}

None.

\section{REFERENCES}

1. Golden MR, Whittington WLH, Handsfield $\mathrm{HH}$, et al. Effect of expedited treatment of sex partners on recurrent or persistent gonorrhea or chlamydial infection. $N$ Engl $J$ Med 2005;352:676-85.

2. Low N, Heijne JCM, Herzog SA, et al. Reinfection by untreated partners of people treated for Chlamydia trachomatis and Neisseria gonorrhoeae: mathematical modelling study. Sex Transm Infect 2014;90:254-256.

3. Estcourt CS, Sutcliffe LJ, Copas A, et al. Developing and testing accelerated partner therapy for partner notification for people with genital Chlamydia trachomatis 
medRxiv preprint doi: https://doi.org/10.1101/2021.08.11.21261692; this version posted August 13, 2021. The copyright holder for this preprint (which was not certified by peer review) is the author/funder, who has granted medRxiv a license to display the preprint in It is made available under a CC-BY 4.0 International license.

diagnosed in primary care: a pilot randomised controlled trial. Sex Transm Infect 2015;91:548-54.

4. Estcourt CS, Howarth AR, Copas A, et al. Accelerated partner therapy (APT) partner notification for people with Chlamydia trachomatis: protocol for the Limiting Undetected Sexually Transmitted infections to RedUce Morbidity (LUSTRUM) APT cross-over cluster randomised controlled trial. BMJ Open 2020;10:e034806.

5. Estcourt CS, Copas A, Low N, et al. Accelerated partner therapy contact tracing for people with chlamydia: The LUSTRUM cluster cross-over randomised controlled trial. medRxiv 2021.08.04.21261369.

6. Althaus $\mathrm{CL}$, Mercer $\mathrm{CH}$, Cassell JA, et al. Investigating the effects of accelerated partner therapy (APT) on chlamydia transmission in Britain: a mathematical modelling study. medRxiv 2020.12.07.20245142.

7. Williams EV, Ogwulu CD, Estcourt CS, et al. The cost-effectiveness of accelerated partner therapy (APT) compared to standard contact tracing for people with chlamydia: an economic evaluation based on the LUSTRUM population-based chlamydia transmission model. medRxiv 2021.07.27.21261128.

8. Public Health England. Partner notification in chlamydia screening - National audit report. 2016.

9. British Association for Sexual Health and HIV (BASHH). Standards for the management of sexually transmitted infections (STIs). 2019.

10. Heijne JCM, Herzog SA, Althaus CL, et al. Insights into the timing of repeated testing after treatment for Chlamydia trachomatis: data and modelling study. Sex Transm Infect 2013;89:57-62. 